\title{
Effect of Cooling of Igneous Rocks on Changes of the Paleointensity in Contact Rocks
}

\author{
J. BochNíčeK, P. HeJdA, and V. KROPÁČEK \\ Geophysical Institute, Czechoslovak Acad. Sci., 14131 Prague, Czechoslovakia
}

(Received January 1990; Revised August 1990)

TRM is generated at the contacts of igneous and sedimentary rocks; it provides information about the paleointensity of the magnetic field at the time the igneous rock was formed. Using a plane model of the intrusion, the process of cooling inside and outside a lava formation is studied by numerical methods depending on the formation's thickness. The effect of crystallization heat on cooling is taken into account.

\section{Introduction}

The loss of the initial magnetic information stored in the rock can have many causes. One of them is the heating of the rock above a certain temperature in the region of lava intrusions. The degree of alteration generally depends on the thickness of the intrusion, the temperature of the lava and the physico-thermal properties of the lava and its ambient environment.

\section{Model of Intrusion}

The process of cooling was theoretically investigated using a model of plane intrusion where in the course of cooling crystallization heat was gradually being released. Considering that heat removal through convection was negligible, the model has full physical plausibility only at sufficient depths below the surface of the earth. The present study proceeds from the work of FEOKTISTOV and FEOKTISTOVA (1972) which is, however, not devoid of certain inaccuracies with respect to the solution of some integrals describing the thermal contributions of individual planparallel-layers into which the intrusion was divided. In the same way as that paper, the solution is divided into two basic parts. The first part describes the dependence of temperature on time and on the coordinate inside the intrusion

$$
T_{1}=P_{1}(t, x)+V_{1}(t, x)
$$

and the second part

$$
T_{2}=P_{2}(t, x)+V_{2}(t, x)
$$

describes the same dependence outside the intrusion; $t$ and $x$ stand for time from the beginning of the process and the distance from the centre of the intrusion respectively. Functions $P_{1 / 2}$ were obtained by combining the ordinary solution of the differential 
equation of heat diffusion by the reflection method, which is well known in electrostatics, while $V_{1 / 2}$ represents the influence of crystallization heat released.

When FEOKTISTOV and FEOKTISTOVA (1972) were deriving the relation for the calculation of $V_{1}$, an error slipped into the integration, which caused a discontinuity of the solution on the boundary as well as high temperatures not corresponding to physical reality in the centre of the intrusion (the difference was $\sim 100^{\circ} \mathrm{C}$ ). In view of the relative inaccessibility of the above work, the authors of the present paper take the liberty of presenting function $T_{2}$ besides the corrected function $T_{1}$.

$$
\begin{aligned}
& P_{1}(t, x)=T_{0}+\frac{T_{p}-T_{0}}{2} \sum_{m=0}^{\infty} A^{m}\left\{\Phi\left[\frac{x-S-2(m-1) S}{2 \sqrt{a_{1} t}}\right]-\Phi\left[\frac{x-S-2 m S}{2 \sqrt{a_{1} t}}\right]\right\} \\
& +\frac{T_{p}-T_{0}}{2} \sum_{m=1}^{\infty} A^{m}\left\{\Phi\left[\frac{x-S+2(m+1) S}{2 \sqrt{a_{1} t}}\right]-\Phi\left[\frac{x-S+2 m S}{2 \sqrt{a_{1} t}}\right]\right\} \\
& V_{1}(t, x)=\frac{q}{2 c_{1}} \sum_{i=1}^{n}\left\{\Phi\left[\frac{x-S+i S / n}{2 \sqrt{a_{1}\left(t-t_{i}\right)}}\right]-\Phi\left[\frac{x-S+(i-1) S / n}{2 \sqrt{a_{1}\left(t-t_{i}\right)}}\right]\right. \\
& \left.+\Phi\left[\frac{x+S-(i-1) S / n}{2 \sqrt{a_{1}\left(t-t_{i}\right)}}\right]-\Phi\left[\frac{x+S-i S / n}{2 \sqrt{a_{1}\left(t-t_{i}\right)}}\right]\right\} \\
& +\frac{q A}{2 c_{1}} \sum_{i=1}^{n}\left\{\Phi\left[\frac{x-S-(i-1) S / n}{2 \sqrt{a_{1}\left(t-t_{i}\right)}}\right]-\Phi\left[\frac{x-S-i S / n}{2 \sqrt{a_{1}\left(t-t_{i}\right)}}\right]\right. \\
& \left.+\Phi\left[\frac{x-3 S+i S / n}{2 \sqrt{a_{1}\left(t-t_{i}\right)}}\right]-\Phi\left[\frac{x-3 S+(i-1) S / n}{2 \sqrt{a_{1}\left(t-t_{i}\right)}}\right]\right\} \\
& P_{2}(t, x)=T_{0}+\frac{\sqrt{a_{1}} B}{\sqrt{a_{2}}}\left(T_{p}-T_{0}\right) \sum_{m=0}^{\infty} A^{m}\left\{\Phi\left[\frac{x-S+2(m+1) S \sqrt{a_{2} / a_{1}}}{2 \sqrt{a_{2} t}}\right]\right. \\
& \left.-\Phi\left[\frac{x-S+2 m S \sqrt{a_{2} / a_{1}}}{2 \sqrt{a_{2} t}}\right]\right\} \\
& V_{2}(t, x)=\frac{q B \sqrt{a_{1}}}{c_{1} \sqrt{a_{2}}} \\
& \times \sum_{i=1}^{n}\left\{\Phi\left[\frac{x-S+i(S / n) \sqrt{a_{2} / a_{1}}}{2 \sqrt{a_{2}\left(t-t_{i}\right)}}\right]-\Phi\left[\frac{x-S+(i-1)(S / n) \sqrt{a_{2} / a_{1}}}{2 \sqrt{a_{2}\left(t-t_{i}\right)}}\right]\right. \\
& +\Phi\left[\frac{x-S+[2 S-(i-1) S / n] \sqrt{a_{2} / a_{1}}}{2 \sqrt{a_{2}\left(t-t_{i}\right)}}\right] \\
& \left.-\Phi\left[\frac{x-S+(2 S-i S / n) \sqrt{a_{2} / a_{1}}}{2 \sqrt{a_{2}\left(t-t_{i}\right)}}\right]\right\} \text {, } \\
& A=\frac{a_{2} \lambda_{1}-\lambda_{2} \sqrt{a_{1} a_{2}}}{a_{2} \lambda_{1}+\lambda_{2} \sqrt{a_{1} a_{2}}}, \quad B=\frac{a_{2} \lambda_{1}}{a_{1} \lambda_{2}+\lambda_{1} \sqrt{a_{1} a_{2}}} \text {. }
\end{aligned}
$$

Here $T_{p}$ is the initial temperature of the lava, $T_{0}$ the temperature of the surroundings, $a_{1 / 2}$ 
the thermal diffusivity of the lava/ambient rock, $\lambda_{1 / 2}$ the thermal conductivity of the lava/ambient rock, $q$ the crystallization heat of the lava, $c_{1 / 2}$ the specific heat of the lava/ambient rock, $S$ the half thickness of the intrusion, $n$ the number of planparallel planes, into which the intrusion will be divided, $t_{i}$ the time, in which the $i$-th layer will crystallize and $\Phi$ is the error-function defined by $\Phi(z)=(2 / \sqrt{\pi}) \int_{0}^{z} \mathrm{e}^{-u^{2}} \mathrm{~d} u$. As $(x+\delta S) /$ $2 \sqrt{a t}=(\alpha x+\delta(\alpha S)) / 2 \sqrt{a\left(\alpha^{2} t\right)}$ holds for the arguments in Expressions (3)-(6), it is evident that the problem is subject to transformation where linear change of the Quantity $S$ is accompanied with linear change of Coordinate $x$ and with quadratic change in time. If the size of the intrusion changes, the size of the thermally metamorphosed contact layer changes proportionally, while the time in which this layer is exposed to the temperature in question changes quadratically. For this reason the description of the course of cooling of intrusions of different thicknesses was abandoned and attention was focused on a single thickness. With a view to achieving a solution as realistic as possible, a thickness of 10 metres was chosen. For the thermophysical properties of the lava and the ambient rock-sandstone in this case-the following values were chosen:

$$
\begin{array}{ll}
\lambda_{1 / 2}=1.66 \mathrm{Wm}^{-1} \mathrm{~K}^{-1}, & \rho_{1}=3120 \mathrm{kgm}^{-3}, \\
q=453.2 \mathrm{kJkg}^{-1}, & \rho_{2}=2500 \mathrm{kgm}^{-3}, \\
c_{1}=0.96 \mathrm{kJkg}^{-1} \mathrm{~K}^{-1}, & a_{1}=5.54 \times 10^{-7} \mathrm{~m}^{2} \mathrm{~s}^{-1}, \\
c_{2}=0.98 \mathrm{kJkg}^{-1} \mathrm{~K}^{-1}, & a_{2}=6.77 \times 10^{-7} \mathrm{~m}^{2} \mathrm{~s}^{-1},
\end{array}
$$

as mean values from the book of SCHÖN (1983) and tables of physical quantities Tablitsy Fizicheskikh Velichin (1976). The initial temperature of the lava was $1250^{\circ} \mathrm{C}$ and the temperature of the surroundings $15^{\circ} \mathrm{C}$.

\section{Results}

On the basis of Eqs. (1)-(7) and constants (8) a number of numerical results was obtained. Some in the form of curves are given in Figs. 1-3.

Figure 1 shows the cooling curves of the plane intrusion depending on Coordinate $x$ inside the intrusion and its immediate surroundings. A parameter of individual curves is time given in hours. From the figure it is evident that in the initial phases of the process considerable thermal gradients arise at the contacts. The dashed curve describes the mode of cooling with no release of crystallization heat -10000 hours after the beginning of the process. If we compare the curve with that of the same parameter, in whose calculation the effect of crystallization heat released was taken into account, we see that the difference is not negligible. For the purpose of the present study, i.e. the quantitative estimate of the size of the thermally metamorphosed contact, it is quite significant.

A detailed view of the contact area is shown in Fig. 2. Solid lines mark two temperature limits, which from our point of view can be regarded as interesting. They are temperatures of $670^{\circ} \mathrm{C}$ and $600^{\circ} \mathrm{C}$. The former is the Neel temperature of hematite and the latter is close to the Curie temperature of magnetite.

Figure 3, which is derived from Fig. 2, shows the thickness of the contact layer exposed to temperatures of $670^{\circ} \mathrm{C}$ and $600^{\circ} \mathrm{C}$ and changing with time. 


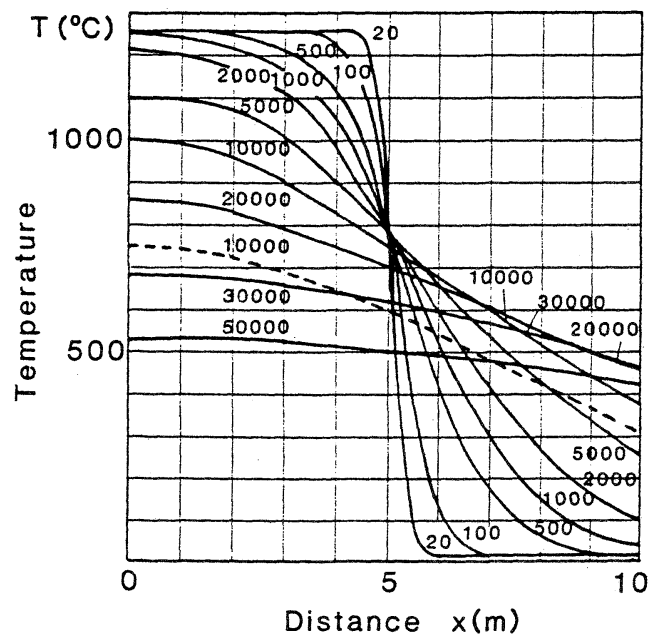

Fig. 1. The dependence of temperature on Coordinate $x$, inside and outside the plane intrusion $10 \mathrm{~m}$ thick. A parameter of individual curves is time, given in hours. The dashed curve shows the change of temperature 10000 hours after the beginning of the process. In calculating it the influence of crystallization heat was disregarded. The lava is melilite nephelinite, the ambient rock-sandstone. The thermophysical parameters of these rocks are given in Eq. (8).

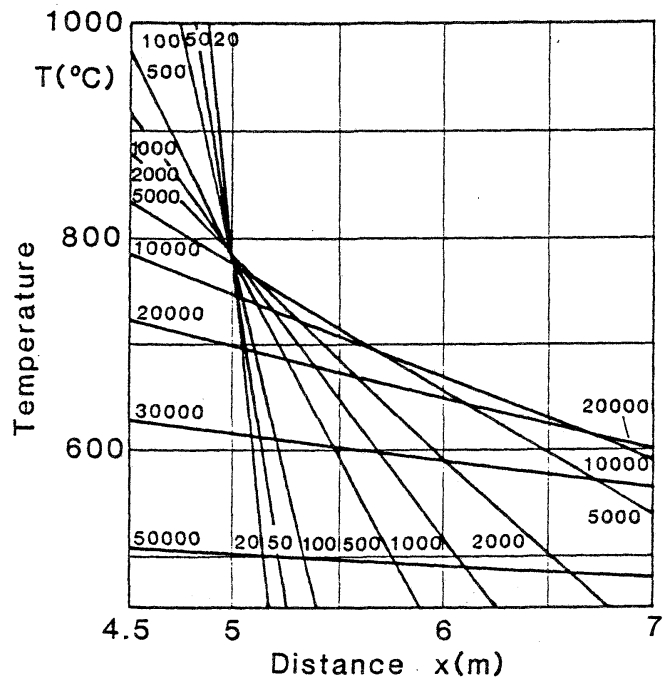

Fig. 2. A detailed view of the zone of lava-sandstone contact. Solid lines mark two temperature limits$670^{\circ} \mathrm{C}$ and $600^{\circ} \mathrm{C}$. The first is the Neel temperature of hematite, the second is close to the Curie temperature of magnetite. The thermophysical parameters are given in Eq. (8). 


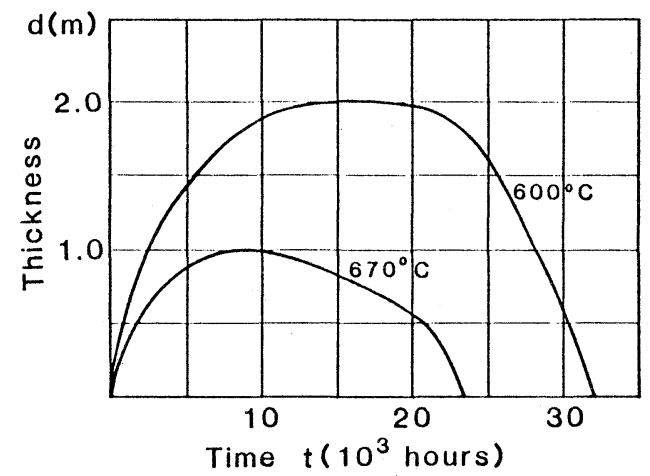

Fig. 3. The thickness of the contact layer, exposed to temperatures of $670^{\circ} \mathrm{C}$ and $600^{\circ} \mathrm{C}$ changing with time. The curves are derived from Fig. 2.

\section{Conclusion}

According to our calculations magnetic changes should take place at contacts, while the size of the contacts depend on the thickness of the intrusion, temperature as well as on thermophysical properties of the lava and its surroundings. In conclusion, we should like to emphasize that in such cases it is important to take into account the influence of the crystallization heat released.

This study was inspired by investigations carried out in a unique geological formation called "The Devil's Wall" located in northern Bohemia. The formation is the shape of a plate approximately $2 \mathrm{~m}$ thick, several kilometers long and very deep.

\section{REFERENCES}

Feoktistov, G. D. and M. F. Feoktistova, O vliyanii skrytoj temperatury kristallizatsii na temperaturnoe pole vblizi plastovykh intruzij trappov, in Matematicheskie Metody v Geologii, 32 pp., Naukova Dumka, Kiev, 1972.

Schön, J., Petrophysik, Ferdinand Enke Verlag, Stuttgart, 1983.

Tablitsy Fizicheskikh Velichin, Atomizdat, Moscow, 1976. 